\title{
Stress evolution in thermal barrier coatings for rocket engine applications
}

\author{
Martin Bäker*, Torben Fiedler and Joachim Rösler
}

\begin{abstract}
Background: Thermal barrier coatings are a promising concept to improve the lifetime of the copper liner of a rocket engine. Due to the high heat fluxes and the large thermal conductivity of copper, coatings have to be designed especially for this application.

Methods: In this paper, we perform fully thermo-mechanically coupled finite element analyses of a small section of a combustion chamber with a coating system comprising a NiCuCrAl bond coat and a NiCrAlY top coat.

Results: Heat fluxes are calculated to determine reasonable coating thickness values. Elastic and plastic deformation in the materials is considered to study the stress evolution. A crack model serves to estimate the possibility of vertical cracks propagating through the coating system.
\end{abstract}

Conclusions: Several design guidelines are developed from these results that will aid future development of thermal barrier coatings.

Keywords: Thermal barrier coating; Finite element modelling; Rocket engine

\section{Background}

The combustion chamber of rocket engines can be exposed to gas temperatures exceeding $3200{ }^{\circ} \mathrm{C}$ (Greuel et al. 2002). Since this is far beyond the service temperature of engineering materials, the chamber wall is cooled on the inside with liquid hydrogen, and a copper alloy with high thermal conductivity is used so that the surface temperature of the copper wall is exposed to temperatures of about $600{ }^{\circ} \mathrm{C}$ (Raj et al. 2007). The strong temperature drop between the process gas and the wall surface is due to the large heat flux that can be in excess of $100 \mathrm{MW} / \mathrm{m}^{2}$ (Popp and Schmidt 1996; Quentmeyer 1977).

Due to the large thermal stresses caused by the high surface temperature, copper liners can fail at the cooling channel. Different failure mechanisms have been discussed, for example ratcheting (Fassin et al. 2014; Quentmeyer 1988) or blanching (cyclic oxidation and reduction in the oxygen/hydrogen atmosphere Ogbuji 2005).

One possibility to avoid failure of the copper is to reduce the surface temperature. This can be achieved with thermal barrier coatings (TBCs), using a material of

*Correspondence: martin.baeker@tu-bs.de

Technische Universität Braunschweig, Langer Kamp 8, 38106 Braunschweig, Germany lower thermal conductivity and higher service temperature. TBC systems have been extensively studied for gas turbine applications (Padture et al. 2002), where a coating system comprising a metallic bond coat (frequently a thermally sprayed NiCrAlY alloy) and a ceramic top coat with very low thermal conductivity are used. Transferring this design directly to rocket engines is problematic, however, because the adhesion of the bond coat to the substrate can be problematic (Schloesser et al. 2011; Schloesser 2014) and because a very thin ceramic top coat would be required to keep the heat flux into the wall sufficiently large and avoid extreme surface temperatures (Kowollik et al. 2013; Schloesser 2014).

A more promising alternative is to use a metallic top coat, for example, a nickel alloy. Recently, a suitable bond coat material, a modified $\mathrm{NiCrAl}$ alloy with added copper, has been developed (Fiedler et al. 2014). One promising coating system thus consists of this material $(\mathrm{Ni} 30 \mathrm{Cu} 6 \mathrm{Al} 5 \mathrm{Cr}$ ) as a bond coat and a standard NiCrAlY (Ni22Cr 10Al 1Y) as a top coat material.

In this paper, we use fully-coupled thermomechanical finite element simulations of this system to study this system and its stress evolution during thermal cycling. The

\section{Springer}

(C) 2015 Bäker et al. Open Access This article is distributed under the terms of the Creative Commons Attribution 4.0 International License (http://creativecommons.org/licenses/by/4.0/), which permits unrestricted use, distribution, and reproduction in any medium, provided you give appropriate credit to the original author(s) and the source, provide a link to the Creative Commons license, and indicate if changes were made. 


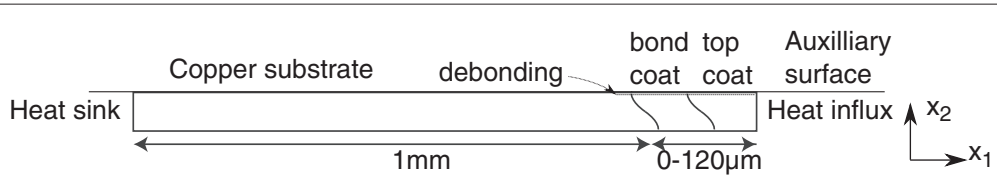

Fig. 1 Geometry of the finite element model

results of these simulations are used to develop some design guidelines for future experiments.

\section{Methods}

\section{Geometry}

The finite element model used in this study is not intended to simulate the full colling channel structure, but only to study the thermal and mechanical behaviour of a thin, representative silce taken out of a cooling channel. The model is that of a two-dimensional slice with a width ( $x_{2}$-direction) of $8.5 \mu \mathrm{m}$, see Fig. 1. The thickness of the substrate is $1 \mathrm{~mm}$; the thickness of the bond coat and the top coat is variable (see section Overall coating thickness). The interface between substrate/bond coat and bond coat/TBC are sinusoidal with an amplitude of $4.5 \mu \mathrm{m}$ and a wavelength of twice the width so that the effect of the interfacial roughness due to a thermal spray process can be studied (Freborg et al. 1998).

Since the model is a thin slice taken out of a larger volume, thermal expansion in the width-direction ( $x_{2}$-direction in the figure) is possible, but the rectangular volume cannot distort. To ensure this, nodes at the lower edge of the model (see Fig. 1) are restricted in $x_{2}$-direction, whereas nodes at the upper edge are bonded in normal direction to an auxilliary straight surface so that their $x_{2}$-displacement is identical. (In the simulation of vertical cracks, some of these nodes are allowed to detach from this surface, see section Vertical crack model). To allow for thermal expansion in the third direction, generalised plane strain conditions have been used.

The model is meshed with approximately 12000 elements (the exact number depends on the thickness of the coating materials). Hybrid first-order elements with reduced integration were used to allow for large plastic deformations without volumetric locking and to avoid shear locking effects at the interface.

\section{Material data}

The material data used in the simuations are given in Tables 1, 2 and 3. The coefficient of thermal expansion (CTE) is the integrated value relative to room temperature. Thermal conductivity and Young's modulus of $\mathrm{NiCuCrAl}$ have not been determined so far; in the simulations they have been assumed to be identical to those of the NiCrAlY bond coat. Simulations in
Table 1 Material data for the copper alloy $\mathrm{CuCr} 1 \mathrm{Zr}$

\begin{tabular}{ll}
\hline $\begin{array}{l}\text { Thermal Conductivity /W/m K } \\
\text { (Kupferinstitut 2005) }\end{array}$ & Temp / K \\
320 & 293.14 \\
315 & 373.14 \\
324 & 473.14 \\
333 & 573.14 \\
336 & 673.14 \\
Coefficient of thermal expansion & Temp / K \\
(Dies 1967; Kupferinstitut 2005) / K & \\
$16.3 \times 10^{-6}$ & 373.14 \\
$17.0 \times 10^{-6}$ & 473.14 \\
$17.6 \times 10^{-6}$ & 573.14 \\
$18.3 \times 10^{-6}$ & 873.14 \\
$19.0 \times 10^{-6}$ & 973.14 \\
$19.8 \times 10^{-6}$ & 1173.14 \\
$20.9 \times 10^{-6}$ & 1356.14 \\
Specific Heat (Kupferinstitut 2005) / & Temp \\
J/kg K & \\
370 & 293.14 \\
450 & 373.14 \\
480 & 473.14 \\
500 & 573.14 \\
500 & 673.14
\end{tabular}

Density (Kupferinstitut 2005) / kg/m³

$8.91 \times 10^{3}$

Young's modulus

(Kupferinstitut 2005) / GPa

120

87 (Fassin 2015)

0.30

293.14

0.31

873.14

Yield stress (Baukloh et al. 1976;

Kupferinstitut 2005; Zinkle and

Fabritsiev 1994) / MPa 
Table 2 Material data for NiCrAlY

\begin{tabular}{|c|c|c|}
\hline $\begin{array}{l}\text { Thermal Conductivity / W/m K } \\
\text { (Altun et al. 2008; } \\
\text { Pawlowski 2008) }\end{array}$ & \multicolumn{2}{|l|}{ Temp /K } \\
\hline 12 & \multicolumn{2}{|l|}{800} \\
\hline 17 & \multicolumn{2}{|l|}{1300} \\
\hline $\begin{array}{l}\text { Coefficient of thermal expansion } \\
\text { (Taylor and Walsh 2004) / } \mathrm{K}^{-1}\end{array}$ & \multicolumn{2}{|l|}{ Temp /K } \\
\hline $13.0 \times 10^{-6}$ & \multicolumn{2}{|l|}{400} \\
\hline $12.9 \times 10^{-6}$ & \multicolumn{2}{|l|}{500} \\
\hline $13.1 \times 10^{-6}$ & \multicolumn{2}{|l|}{600} \\
\hline $13.4 \times 10^{-6}$ & \multicolumn{2}{|l|}{700} \\
\hline $13.7 \times 10^{-6}$ & \multicolumn{2}{|l|}{800} \\
\hline $14.0 \times 10^{-6}$ & \multicolumn{2}{|l|}{900} \\
\hline $14.3 \times 10^{-6}$ & \multicolumn{2}{|l|}{1000} \\
\hline $15.6 \times 10^{-6}$ & \multicolumn{2}{|l|}{1100} \\
\hline $19.0 \times 10^{-6}$ & \multicolumn{2}{|l|}{1400} \\
\hline Specific Heat * / J/kg K & \multicolumn{2}{|l|}{ Temp } \\
\hline 460 & \multicolumn{2}{|l|}{343.14} \\
\hline 410 & \multicolumn{2}{|l|}{473.14} \\
\hline 330 & \multicolumn{2}{|l|}{673.14} \\
\hline 230 & \multicolumn{2}{|l|}{873.14} \\
\hline 400 & \multicolumn{2}{|l|}{1073.14} \\
\hline 1440 & \multicolumn{2}{|l|}{1273.14} \\
\hline 1370 & \multicolumn{2}{|l|}{1373.14} \\
\hline \multicolumn{3}{|l|}{ Density / kg/m³ } \\
\hline \multicolumn{3}{|l|}{$6.9 \times 10^{3}$} \\
\hline $\begin{array}{l}\text { Young's modulus } \\
\text { (Margadant et al. 2006) / GPa }\end{array}$ & $\begin{array}{l}\text { Poisson's ratio } \\
\text { (Taylor and } \\
\text { Bettridge 1996) }\end{array}$ & Temp /K \\
\hline 120 & 0.3 & 293.14 \\
\hline 100 & 0.3 & 673.14 \\
\hline 80 & 0.3 & 1073.14 \\
\hline 70 & 0.3 & 1273.14 \\
\hline Yield stress */MPa & Temp / K & \\
\hline 1200 & 294.14 & \\
\hline 1200 & 773.14 & \\
\hline 900 & 873.14 & \\
\hline 380 & 973.14 & \\
\hline 100 & 1073.14 & \\
\hline 60 & 1173.14 & \\
\hline
\end{tabular}

Data labelled with an asterisk are based on own unpublished measurements

Section Overall coating thickness and Elastic stress evolution were done using elastic material properties without taking plasticity into account. The material behaviour is actually dominated by creep at high temperatures; however, since the main effect of creep is to cause stress relaxation at high temperatures (so that thermal stresses
Table 3 Material data for NiCrCuAl

\begin{tabular}{|c|c|}
\hline $\begin{array}{l}\text { Thermal Conductivity }+ \text { / } \\
\mathrm{W} / \mathrm{m} \mathrm{K}\end{array}$ & Temp / \\
\hline 12 & 800 \\
\hline 17 & 1300 \\
\hline $\begin{array}{l}\text { Coefficient of thermal expansion } \\
\text { (Fiedler et al. 2014) / } \mathrm{K}^{-1}\end{array}$ & Temp / \\
\hline $13.7 \times 10^{-6}$ & 323.14 \\
\hline $14.6 \times 10^{-6}$ & 423.14 \\
\hline $14.9 \times 10^{-6}$ & 523.14 \\
\hline $14.6 \times 10^{-6}$ & 623.14 \\
\hline $14.2 \times 10^{-6}$ & 723.14 \\
\hline $14.3 \times 10^{-6}$ & 823.14 \\
\hline $14.8 \times 10^{-6}$ & 923.14 \\
\hline $16.0 \times 10^{-6}$ & 1023.14 \\
\hline $17.7 \times 10^{-6}$ & 1123.14 \\
\hline $18.9 \times 10^{-6}$ & 1223.14 \\
\hline $19.9 \times 10^{-6}$ & 1323.14 \\
\hline $20.46 \times 10^{-6}$ & 1393.14 \\
\hline Specific Heat * / J/kg K & Temp \\
\hline 480 & 293.14 \\
\hline 490 & 400 \\
\hline 460 & 600 \\
\hline 400 & 700 \\
\hline 350 & 800 \\
\hline 370 & 900 \\
\hline 400 & 950 \\
\hline 530 & 1000 \\
\hline 630 & 1050 \\
\hline 620 & 1100 \\
\hline 630 & 1200 \\
\hline
\end{tabular}

Density * $/ \mathrm{kg} / \mathrm{m}^{3}$

$$
7.7 \times 10^{+3}
$$

Young's modulus $\mathbf{t} / \mathrm{GPa}$

$\begin{array}{ll}\text { Poisson's ratio } & \text { Temp / K } \\ 0.3 & 293.14 \\ 0.3 & 673.14 \\ 0.3 & 1073.14 \\ 0.3 & 1273.14\end{array}$

Temp / K

294.14

473.14

773.14

823.14

873.14

973.14

1073.14

Data labelled with an asterisk are based on own unpublished measurements, data Data labelled with an asterisk are based on own unpublished
labelled with a dagger are assumed to be identical to NiCrAly 
develop on cooling), using plastic behaviour instead can be expected to lead to similar results. The temperaturedependent yield stress has been measured in compression tests of free-standing coatings for temperatures up to $800{ }^{\circ} \mathrm{C}$ for $\mathrm{NiCuCrAl}$ and up to $900{ }^{\circ} \mathrm{C}$ for NiCrAlY; values above that are estimates. Since large stresses evolve during cooling, the exact value of the yield stress at high temperatures does not strongly affect the final stresses in the coating as long as it is sufficiently small.

\section{Thermal boundary conditions}

The temperature in the hydrogen cooling channel was assumed to be $70 \mathrm{~K}$. This temperature was also chosen as the initial temperature of the model. A film cooling condition with a heat transfer coefficient of $145 \mathrm{kWm}^{-2} \mathrm{~K}^{-1}$ was assumed at this side. On the hot side with gas temperature of $3410 \mathrm{~K}$, a surface-temperature dependent film condition was assumed. Due to this film condition, the surface temperature of wall is considerably lower than the hot gas temperature, since it is determined by the heat flux and the equation $\dot{q}=\alpha \Delta T$, where $\dot{q}$ is the heat flux per unit area, $\alpha$ the heat transfer coefficient and $\Delta T$ the temperature difference between hot gas and surface temperature (Bürgel et al. 2011). Values for the heat transfer coefficient are listed in Table 4. All data for the thermal boundary conditions were taken from a coupled FSI-model of the rocket engine (Kowollik 2015).

For a full cycle, heating was switched on for one second to ensure stationary conditions (a stationary state is reached after about $0.2 \mathrm{~s}$, see Fig. 4 below), and then switched off again for 1 second so that the whole structure cooled down again to $70 \mathrm{~K}$. No radiative heat transfer at the hot side was assumed.

\section{Vertical crack model}

Large tensile stresses and (cyclic) plastic strains in the $x_{2}$ - and $x_{3}$-direction develop in the model with plasticity after cooling. These stresses and strains can be expected to cause cracks perpendicular to the surface of the coating ( $x_{1}$-direction in Fig. 1). These cracks are called "vertical cracks", in the following. (Similar cracks, usually called "segmentation cracks", are frequently observed in ceramic TBCs (Seiler et al. 2013). These cracks are caused during first heating to service temperature by the mismatch in thermal expansion. Since this is a different mechanism from the one discussed here, the term "segmentation crack" is not used in this paper). To study this possibility, the model was extended to allow debonding of the nodes in the top and bond coat of the system after cooling down. Nodes were debonded using a timecontrolled debonding criterion, and the total energy of the model was calculated during the debonding process. This allows to calculate the energy release rate and thus to
Table 4 Temperature-dependent heat transfer coefficient at the hot side of the copper liner (Kowollik 2015)

\begin{tabular}{ll}
\hline Temperature / K & Heat transfer $/ \mathrm{Wm}^{-2} \mathrm{~K}^{-1}$ \\
\hline 70 & 53779 \\
167 & 55244 \\
348 & 54881 \\
562 & 52877 \\
748 & 50754 \\
873 & 49326 \\
937 & 48637 \\
962 & 48404 \\
968 & 48354 \\
969 & 48349 \\
1031 & 47623 \\
1138 & 46374 \\
1259 & 45004 \\
1361 & 43901 \\
1427 & 43235 \\
1461 & 42941 \\
1474 & 42849 \\
1477 & 42830 \\
1478 & 42827 \\
\hline
\end{tabular}

estimate whether vertical cracks might propagate to the copper substrate.

\section{Results and discussion}

\section{Overall coating thickness}

In a first study, the total coating thickness was varied between $0 \mu \mathrm{m}$ and $120 \mu \mathrm{m}$, using the same thickness for bond coat and top coat (since the thermal conductivity of both materials is assumed to be the same, varying the relative thickness of the two coatings does not affect the temperature profile). Figure 2 shows the maximum temperature at the surface of the structure and in the copper substrate as a function of overall coating thickness. As expected, the surface temperature increases with increasing thickness due to a reduced heat flux (Bürgel et al. 2011), whereas the temperature of the copper substrate decreases significantly. If we assume a maximum service temperature of $1150{ }^{\circ} \mathrm{C}$ for the top coat, a coating thickness of $90 \mu \mathrm{m}$ can be chosen. At this thickness, the maximum temperature of the copper substrate reduces by $200 \mathrm{~K}$ from $1122 \mathrm{~K}$ to $922 \mathrm{~K}$. This reduction can be expected to strongly reduce creep in the material. In the subsequent studies discussed in the next sections, the total coating thickness was therefore fixed at $90 \mu \mathrm{m}$.

The temperature distribution in the coating is shown in Fig. 3. As expected, the temperature rapidly increases 


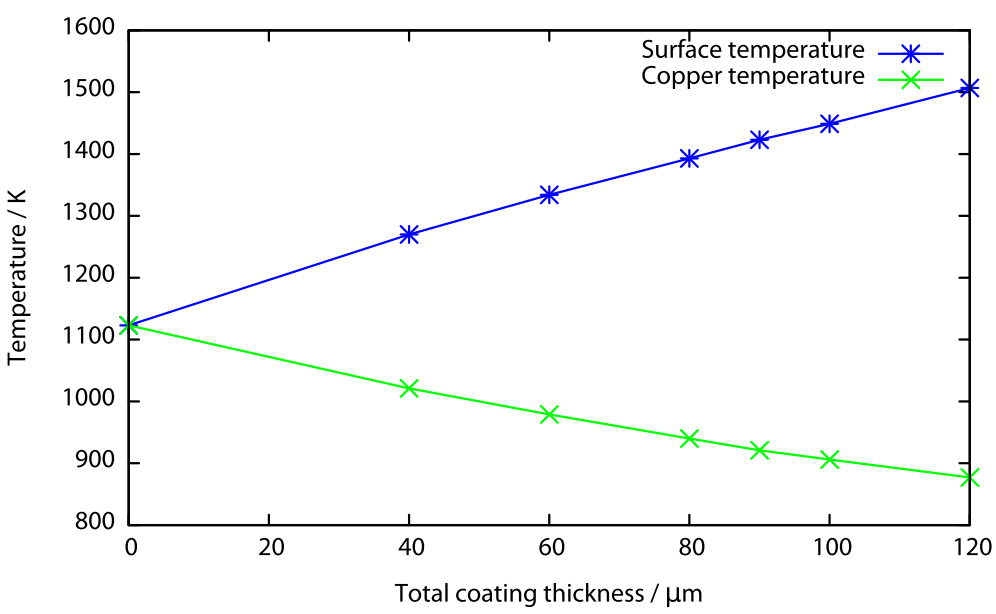

Fig. 2 Surface temperature and maximum copper temperature for different total coating thicknesses

in the coating, whereas the copper substrate lags behind due to the thermal insulation effect. A strong temperature gradient evolves in the thermal barrier coating. (The small deviation from a linear function at the bond coat/copper interface is due to the sinusoidal shape of the interface).

Figure 4 shows the temperature history for points located in the middle of each of the three materials for the case of $45 \mu \mathrm{m}$ bond coat and $45 \mu \mathrm{m}$ top coat. A stationary state is reached after less than $0.2 \mathrm{~s}$. The figure also shows the temperature difference between the copper substrate and the top coat. Due to its lower thermal conductivity and the vicinity to the heat source, the top coat heats up considerably faster than the substrate, leading to a maximum in the temperature difference. This will become important in section Plastic stress evolution.

\section{Elastic stress evolution}

In gas turbine applications, failure of thermal barrier coatings is driven by microcracks developing at the interface

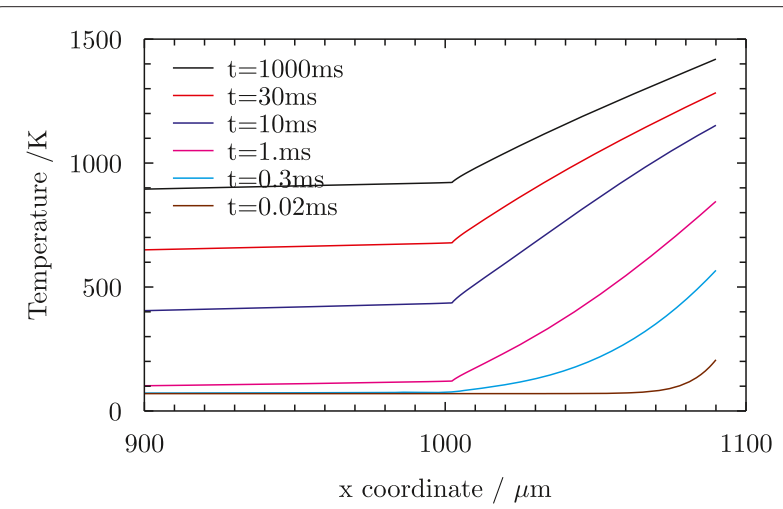

Fig. 3 Temperature evolution in the upper $100 \mu \mathrm{m}$ of the copper substrate and the coating on the lower edge of the model for a coating thickness of $90 \mu \mathrm{m}$ between the top coat and the bond coat, where a thermally grown oxide layer forms. These cracks are due to growth stresses and thermal mismatch stresses at the interface in the direction vertical to the interface ( $x_{1}$-direction in the geometry of Fig. 1 ). In a rocket engine, the high temperature exposure time is too short for a critical oxide layer to form. Furthermore, since the difference in the CTE is smaller in the coatings considered here, the thermal mismatch stresses are actually rather moderate. Figure 5 shows the stresses calculated in the purely elastic model at the end of hold time. Maximum tensile stresses are below $140 \mathrm{MPa}$. If all stresses would relax during hot time, cooling stresses of similar magnitude and opposite sign can be expected after cooling (see also Fig. 10 below).

In addition to these stresses, the in-plane stresses may be important because they contribute to bending and buckling of the coating. Figure 6 shows the elastic stress

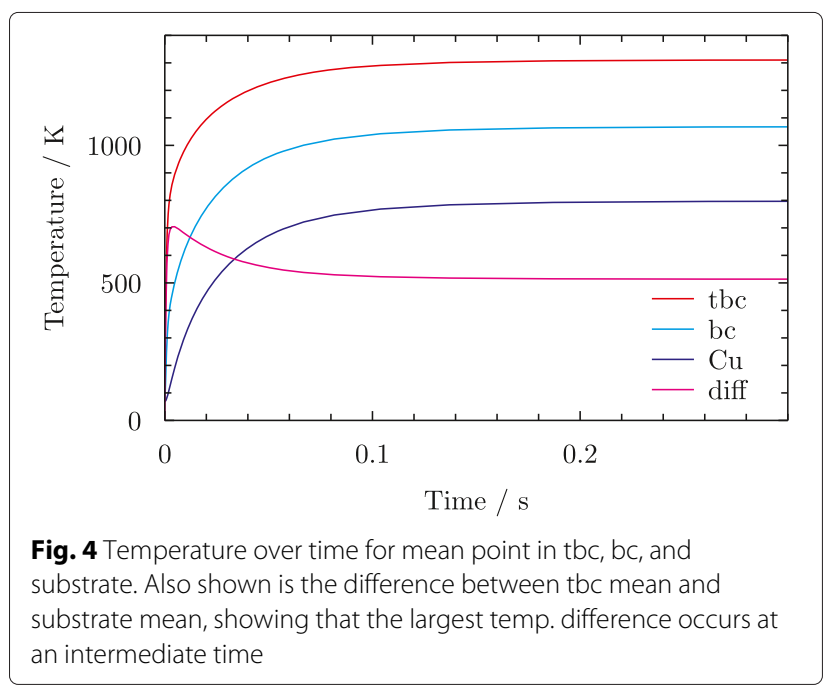



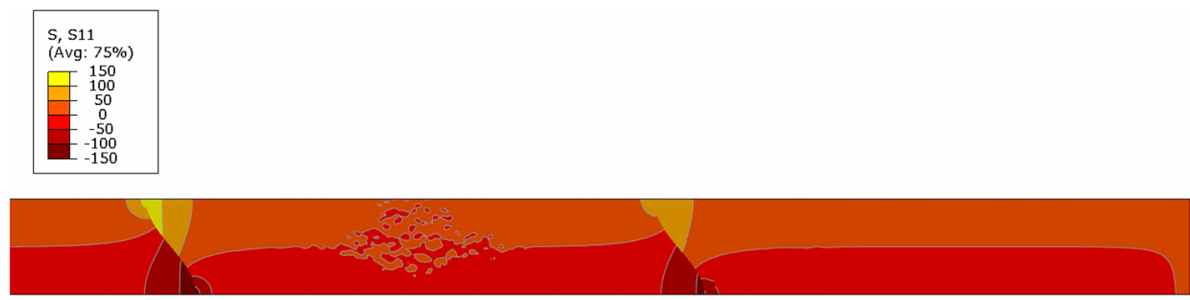

Fig. 5 Elastic stresses in 11-direction at the end of the heating step

in 22-direction for three different coating thicknesses (bc/tbc) $45 \mu \mathrm{m} / 45 \mu \mathrm{m}, 30 \mu \mathrm{m} / 60 \mu \mathrm{m}$, and $20 \mu \mathrm{m} / 70 \mu \mathrm{m}$. As can be seen, large compressive stresses develop at the interface for equal thicknesses of tbc and bond coat; these stresses are reduced and the stress profile becomes more homogeneous if the bond coat thickness is reduced. Note that after stress relaxation, the coating will be under tension in the in-plane direction when cooled down.

\section{Plastic stress evolution}

In the previous section, thermal stresses generated during heating have been calculated. These stresses can also be used to estimate stresses after cooling under the simplifying assumption that all stresses relax during hot time. Although this assumption is plausible in the coating where temperatures are large, stresses in the copper substrate will not relax fully. This has a strong effect on the in-plane stresses in the coating.

To study the effect of plastic deformation in greater detail, temperature-dependent plasticity is assumed in the materials. Figure 7 shows the 22-stress at the end of the heating time and after cooling down. On first sight, it may be surprising to see that tensile stresses develop at the top of the coating where the temperature is largest and where therefore maximum thermal expansion can be expected. The reason for this is the transient maximum in the temperature difference between coating and substrate shown in Fig. 4. This leads to a large difference in thermal strains during the initial heating phase, causing plastic flow in the top of the coating. Upon further heating, the temperature difference decreases so that tensile stresses can develop. (It should be noted that, since the transient maximum of the temperature difference occurs only for a very short time, hardening due to rate-dependent plasticity might reduce this effect. This has not been taken into account here because material data are not available and because the details of the ignition of the rocket engine are not represented in the heat flux as defined in Table 4).

After cooling to room temperature, large thermal strains develop in the coating leading to large in-plane tensile stresses in the coating, see Fig. 7b. The possibility of vertical cracks driven by these stresses will be discussed in section Vertical cracks.

Figure 8 shows a plot of the elastic strain in the coating versus temperature. If all materials are elastic, the strain history is completely reversible so that no changes occur when several cycles are performed. For the case with plasticity, the plastic deformation during heating in the first cycle causes a decrease of the elastic strain as explained above, so that the first cycle differs from subsequent cycles. After the first cycle (4 cycles are shown in the figure), no further change occurs because there is no further plastic deformation.

\section{CTE influence}

From the results shown in the previous sections, it is obvious that the stress in the coating is governed by the interplay of the temperature gradient and the CTE mismatch. One possibility to reduce these stresses would be to tailor the CTE of the coating material so that the

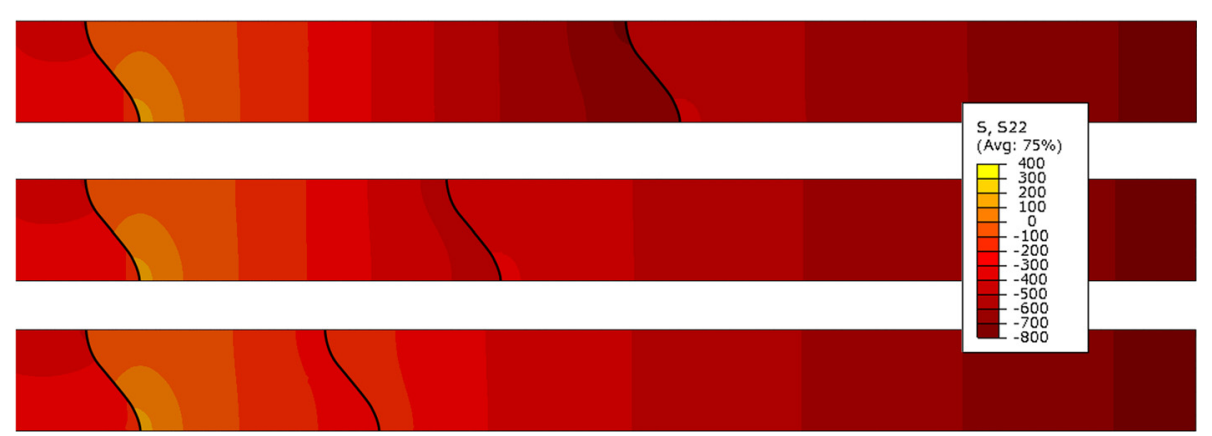

Fig. 6 Elastic stresses in 22-direction at the end of the heating step for three different thicknesses of bond coat and tbc 

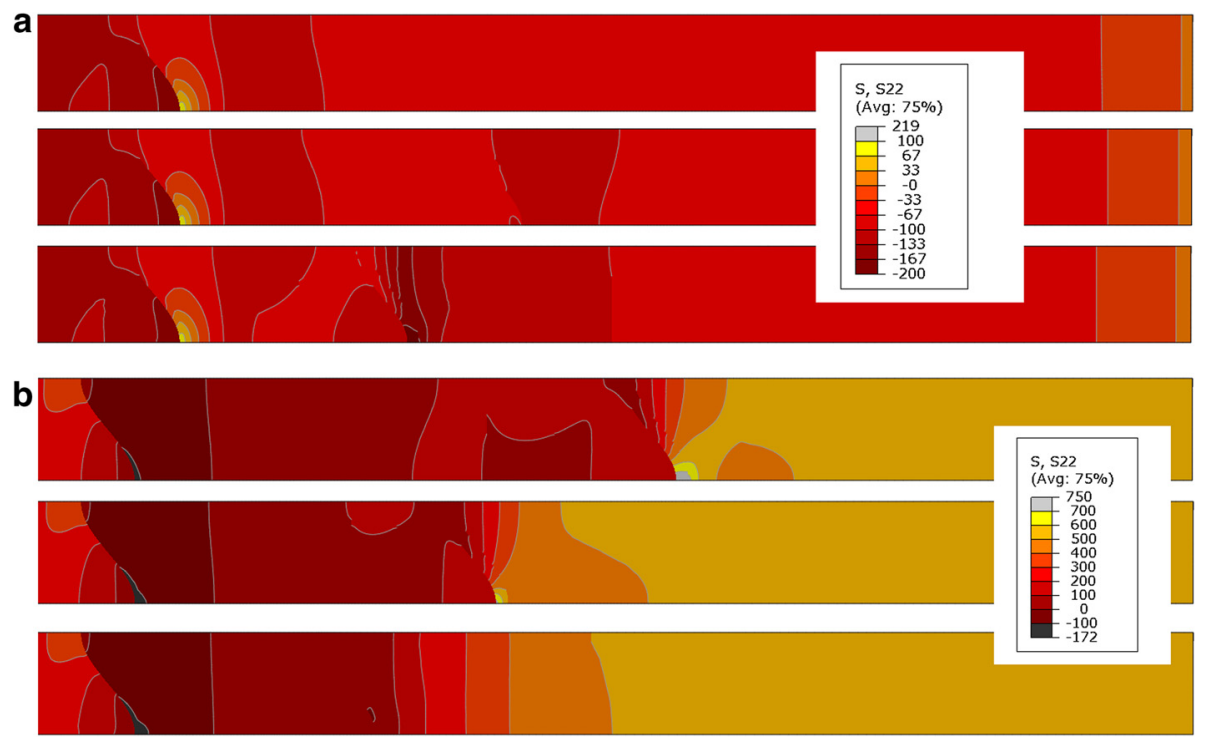

Fig. 7 Stresses in 22-direction in the coating at the end of heating and cooling with plasticity for three different thicknesses of bond coat and tbc. a End of heating time. $\mathbf{b}$ End of cooling time

thermal strain in the coating is the same as the strain prescribed by the copper substrate.

In the elastic case, the calculated temperature field (Fig. 3) can be used to calculate the thermal strains at each position. Based on this, the CTE needed to ensure a stress-free coating at the end of the heating period can be calculated as a function of temperature (Fig. 3). This is shown in Fig. 9. As expected, the CTE should reduce with temperature to avoid compressive stresses in the coating close to the surface. Since the CTE in standard materials increases with temperature, this temperature dependence of the CTE could only be achieved by varying the material, e. g. by applying a graded coating. However, the absolute

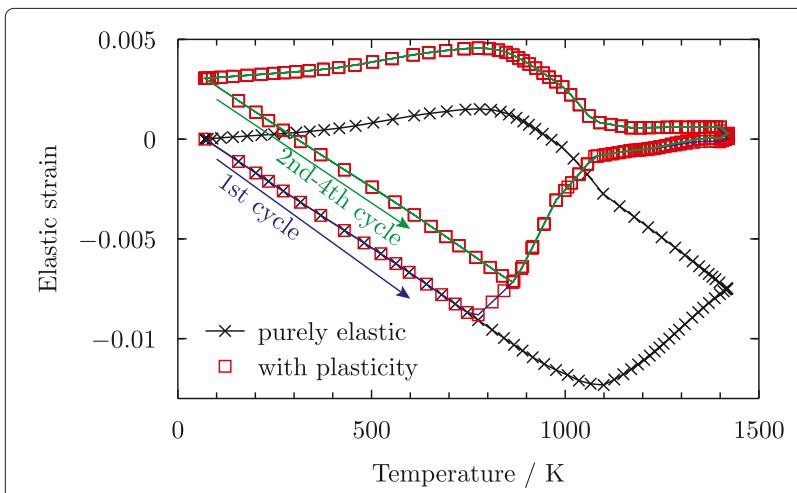

Fig. 8 Evolution of temperature vs. elastic strain with and without plasticity for a material point at the coating's surface for a coating thickness of $45 \mu \mathrm{m} / 45 \mu \mathrm{m}$. For the elastic case, there is no change in the strains if several cycles are performed; for the plastic case, the first cycle differs from subsequent cycles, but no changes occur after the second cycle since there is no further plastic deformation value of the CTE at the highest temperature is unrealistically small for a metallic coating (Touloukian et al. 1975) so that it seems unrealistic to create a stress-free coating in this manner. Furthermore, plastic deformation has a considerable effect on the developing strains which also affects the role of the CTE. In the purely elastic case, the strain at the surface at the end of hot time is approximately 0.75 \% (Fig. 8); the calculated CTE for a stress-free state at the highest temperature in Fig. 9 is based on this value. If plastic deformation is taken into account, the strain at the end of hot time is very small, so the ideal CTE should be based on the residual strain after cooling. This value is approximately $0.3 \%$ and is thus considerably smaller so that the desired reduction in the CTE should be correspondingly smaller.

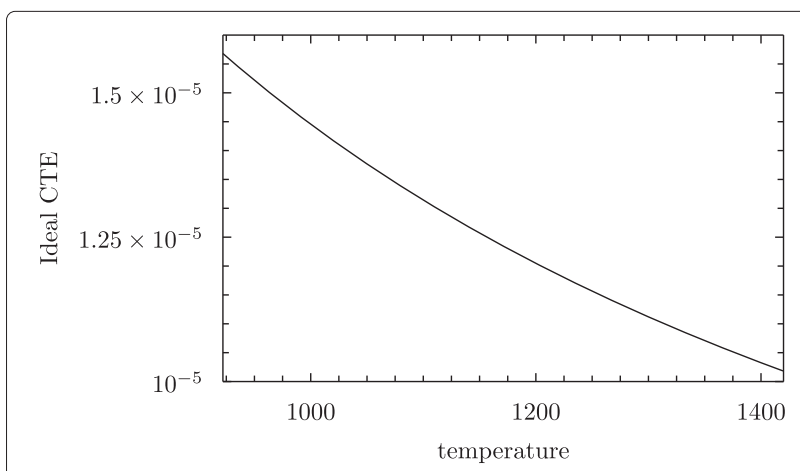

Fig. 9 Theoretically calculated CTE vs temperature (in K) in the coating that would result in vanishing stresses at the end of hold time for the purely elastic case 

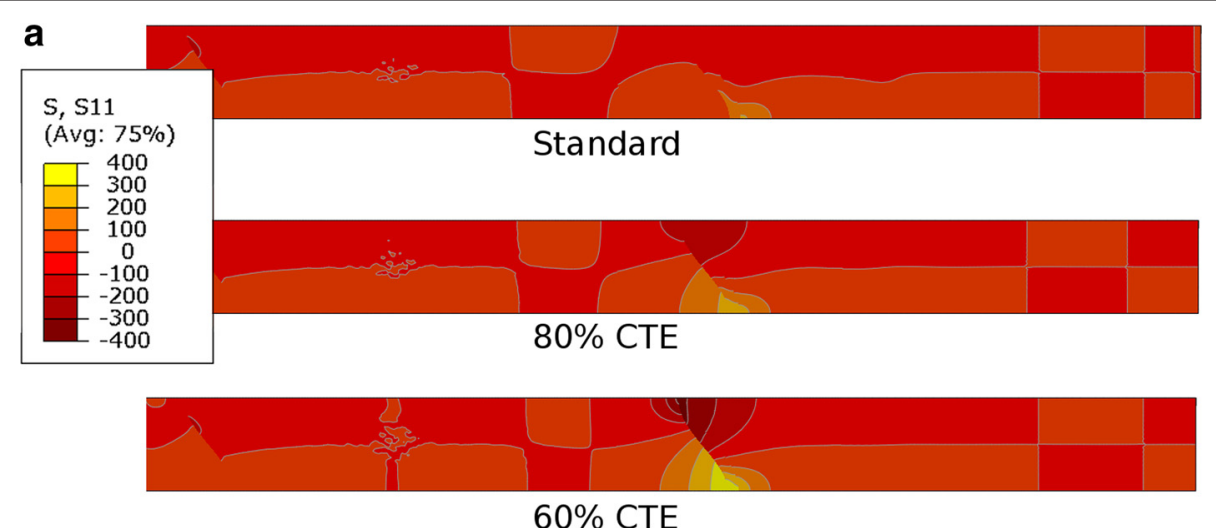

$60 \%$ CTE

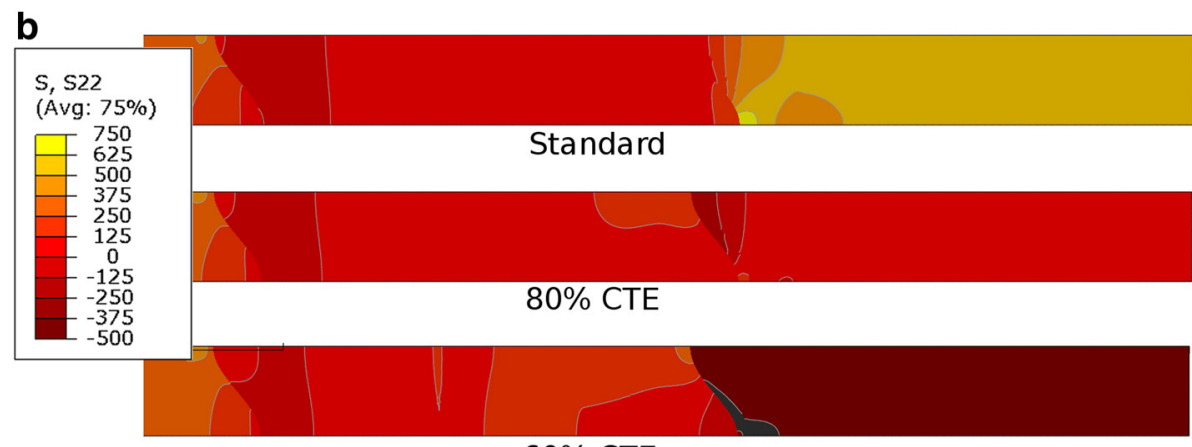

$60 \%$ CTE

Fig. 10 Stress field for reduced CTE in the coating at the end of the cooling step. a Stress in 11-direction. b Stress in 22-direction

To further evaluate the effect of changing the CTE, simulations with a reduced CTE $(80 \%$ and $60 \%$ of the standard value from Table 2) in the top coat material have been performed, using the model with plasticity. The resulting stress fields are shown in Fig. 10. The in-plane stresses after cooling in the coating reduce to less than 100 $\mathrm{MPa}$ for the case of a CTE reduction to $80 \%$. If the CTE is reduced further, the top-coat material is actually in inplane compression. From this, it seems that reducing the CTE might be a possible way of reducing the danger of vertical cracks.

However, since the CTE of the bond coat has not been changed, the interfacial 11-stresses increase so that the reduction of the in-plane stresses is accompanied by an increase of the interfacial stresses. The maximum tensile stress after cooling increases from about $210 \mathrm{MPa}$ to more than $380 \mathrm{MPa}$, so that the danger of interfacial cracks increases. Using a graded coating, this effect could be reduced.

Overall, it seems that choosing a top coat material with a smaller CTE than NiCrAIY (possibly together with a graded coating structure) might be beneficial to reduce the stresses.

\section{Vertical cracks}

To study the possibility of vertical cracks forming in the coating after cooling, a node release technique as described in section Vertical crack model has been used for the two coating thicknesses $45 \mu \mathrm{m} / 45 \mu \mathrm{m}$ and $20 \mu \mathrm{m} / 70 \mu \mathrm{m}$. Figure 11 shows the elastically stored energy $W$ per unit thickness in the model as a function of the crack length $a$. A linear fit was used in the top coat and bond coat regime to calculate the energy release rate $G=\mathrm{d} W / \mathrm{d} a$. The calculated energy release rate in the

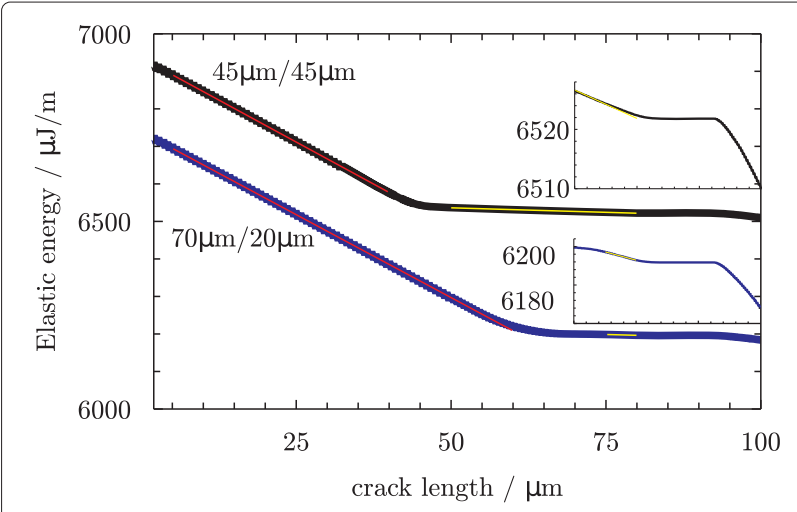

Fig. 11 Stored energy per unit thickness for vertical crack propagation with coating thickness $45 \mu \mathrm{m} / 45 \mu \mathrm{m}$ and $20 \mu \mathrm{m} / 70 \mu \mathrm{m}$. The straight lines are fit lines used in the top coat and bond coat region, resp. The inset figures show a zoom of the energy change near the copper-bond coat interface 
top coat is $G_{45 / 45}^{\text {top }}=8.96 \mathrm{~J} / \mathrm{m}^{2}$ and $G_{20 / 70}^{\text {top }}=8.84 \mathrm{~J} / \mathrm{m}^{2}$ for the two different geometries. In the bond coat, the values are considerably smaller: $G_{45 / 45}^{\mathrm{bc}}=0.48 \mathrm{~J} / \mathrm{m}^{2}$ and $G_{20 / 70}^{\text {bc }}=0.43 \mathrm{~J} / \mathrm{m}^{2}$. Close to the interface (see the insets in Fig. 11), the energy stays constant during crack propagation because the stress state is compressive. In the region directly adjacent to the interface, the tensile stresses in the copper cause an increase of the energy release.

The lower value of the energy release rate in the bond coat is not due to its larger CTE, but rather to its lower yield stress. At temperatures between 1100 and $900 \mathrm{~K}$ during the cooling process, where the temperature difference to the substrate is larger, the bond coat yields plastically and thus strongly reduces the thermal strains.

Note that the mirror symmetry employed in the model means that the distance between two vertical cracks is twice the thickness of the model, i.e. $17 \mu \mathrm{m}$. Since the stress field is almost homogeneous in the coating (at some distance from the interfaces), the stored energy is proportional to the thickness of the model. This can be used to estimate the distance between vertical cracks. If the critical energy release rate in the top coat is $G_{c}^{\text {top }}$, the distance between vertical cracks should be of the order of $17 \mu \mathrm{m} \cdot G_{c}^{\text {top }} / G_{\text {measured }}^{\text {top }}$.

The critical energy release rate at the interface between a plasma-sprayed NiCrAlY bond coat and a nickel substrate is of the order of $150 \mathrm{~J} / \mathrm{m}^{2}$ (Clyne and Gill 1996). Vertical cracks inside the coating can be expected to have a larger energy release rate. If we assume a value of $250 \mathrm{~J} / \mathrm{m}^{2}$, a typical distance between vertical cracks will be approximately $500 \mu \mathrm{m}$.

These cracks will not propagate into the bond coat because the energy release rate is strongly reduced there due to plastic deformation on cooling that reduces thermal strains. It is of course still possible that some of the cracks propagate into the bond coat, but the distance of vertical cracks in the bond coat can be expected to be larger. Due to the compressive stress in the bond coat close to the copper interface, these cracks will probably not propagate into the substrate.

The energy release rate in the top and bond coat does not depend strongly on the thickness of the two coating components. Therefore, although the stress calculation itself seems to favour a thinner bond coat, this will lead to deeper vertical cracks. Since the energy release rate in the top part of the copper substrate is larger than in the bond coat, a sufficient thickness of the bond coat is probably helpful to ensure that no vertical cracks reach in the substrate.

\section{Conclusions}

In this paper, a finite element model of a metallic thermal barrier coating system in a rocket engine has been studied.
The following conclusions and design guidelines can be drawn:

- In a $\mathrm{NiCrAlY} / \mathrm{NiCuCrAl-TBC}$, a reasonable coating thickness is $90 \mu \mathrm{m}$. This reduces the substrate temperature by approximately $200 \mathrm{~K}$.

- Interface stresses in thickness direction are rather small both at the substrate/bc and at the bc/tbc interface, so that crack propagation at the interface is expected to be less pronounced than in gas turbine applications.

- In-plane stresses can become large in the system. If stresses relax at high temperatures, large tensile stresses can be expected after cooling.

- The thickness ratio bc/tbc strongly influences the stress field. A thin bond coat leads to a smooth stress field with no local maxima, however, it may also lead to deeper vertical cracks.

- Plasticity in the coating changes the stress field considerably and may even lead to tensile stresses at the hot time due to a transient maximum in the temperature difference between coating and substrate. Thus it is important to evaluate the temperature history during the ignition of the engine.

- Reducing the CTE of the top coat will reduce in-plane stresses, However, if the value is too small, the increase in the interface stresses in thickness direction may offset the advantages of a reduced CTE. Nevertheless, choosing a top coat material with a smaller CTE, possibly together with applying a graded coating, may be a promising way of optimising the coating.

- Due to the large tensile stresses in the top coat after cooling down, a vertical crack network can be expected to form in the top coat. The critical energy release rate for propagation in the bond coat is considerably smaller so that most vertical cracks can be expected to stop upon reaching the bond coat.

To optimize the ratio of the top coat/bond coat thickness, the following effects need to be considered: (i) the transient temperature maximum, (ii) the reduction of in-plane stress gradients when the bond coat is thin, (iii) the propagation of vertical cracks through the bc into the substrate. To evaluate these effects in detail, experiments under realistic conditions are needed to understand the dominating failure mechanisms.

\section{Competing interests \\ The authors declare that they have no competing interests.}

\section{Authors' contributions}

$M B$, TF and JR designed the study. TF performed material measurements. MB created the model, performed and post-processed the simulations. MB, TF and $J R$ evaluated and interpreted the results. MB wrote the first draft. MB, TF and JR revised and approved the manuscript. 


\section{Acknowledgements}

Financial support by the German Research Foundation (Deutsche Forschungsgemeinschaft/DFG) in the framework of the Sonderforschungsbereich Transregio 40, Teilprojekt D2 is gratefully acknowledged. Data on the heat transfer were kindly provided by Matthias Haupt and Daniel Kowollik, Technische Universität Braunschweig.

Received: 22 June 2015 Accepted: 26 August 2015

Published online: 05 September 2015

\section{References}

Altun O, Boke YE, Kalemtas A (2008) Problems for determining the thermal conductivity of TBCs by laser-flash method. J Achiev Mater Manuf Eng 30:115-120

Bürgel R, Maier HJ, Niendorf T (2011) Handbuch HochtemperaturWerkstofftechnik. Vieweg, Wiesbaden

Baukloh A, Drehfahl K, Heubener U, Rühle M (1976) Zeitstandsuntersuchungen an niedrig- und unlegierten Kupferwerkstoffen. Metall 30(1):19-28

Clyne TW, Gill SC (1996) Residual stresses in thermal spray coatings and their effect on interfacial adhesion: A review of recent work. J Therm Spray Tech 5(4):401-418. doi:10.1007/BF02645271

Dies K (1967) Kupfer und Kupferlegierungen in der Technik. Springer, Heidelberg

Fassin M (2015) Poissons Ratio of CuCr1Zr. Institute of Applied Mechanics RWTH Aachen University, private communication

Fassin M, Tini V, Vladimirov I, Reese S (2014) Life prediction of a rocke combustion chamber wall by a viscoplastic damage model. Proc Appl Math Mech 14:149-150

Fiedler T, Fedorova T, Rösler J, Bäker M (2014) Design of a nickel-based bond-coat alloy for thermal barrier coatings on copper substrates. Metals 4:503-518

Freborg AM, Ferguson BL, Petrus GJ, Brindley WJ (1998) Modeling oxidation induced stresses in thermal barrier coatings. Mater Sci Eng A245:182-190. Chap. 207429

Greuel D, Suslov D, Haidn O, Fritscher K (2002) Thermal barrier coatings for cryogenic rocket engines. AIAA J 1:4145

Kowollik DSC, Horst P, Haupt MC (2013) Fluid-structure interaction analysis applied to ther barrier coated cooled rocket thrust chamber with subsequent local investigation of delamination phenomena. Prog Propuls Phys 4:617-636

Kowollik D (2015) Private Communication

Kupferinstitut D (ed) (2005) Kupferdatenblatt CuCr1Zr. Deutsches Kupferinstitut, (German Copper institute. https://www.kupferinstitut.de/ fileadmin/user_upload/kupferinstitut.de/de/Documents/Shop/Verlag/ Downloads/Werkstoffe/Datenblaetter/Niedriglegierte/CuCr1Zr.pdf, see also https://www.kupferinstitut.de/de/persoenlicheberatung/shopverlagdownloads/downloads/werkstoffe/werkstoff-datenblaetter.htm

Margadant N, Neuenschwander J, Stauss S, Kaps H, Kulkarni A, Matejicek J, Rössler G (2006) Impact of probing volume from different mechanical measurement methods on elastic properties of ththermal sprayed Ni-based coatings on a mesoscopic scale. Surf Coat Technol 200:2805-2820

Ogbuji L (2005) A table-top technique for assessing the blanching resistance of cu alloys. Oxid Met 63(5-6):383-399

Padture NP, Gell M, Jordan EH (2002) Thermal barrier coatings for gas-turbine engine applications. Science 296(5566):280-284

Pawlowski L (2008) Science and Engineering of Thermal Spray Coatings. John Wiley \& Sons Ltd., Hoboken, NJ

Popp M, Schmidt G (1996) Rocket Engine Combustion Chamber Design Concepts for Enhanced Life. In: AIAA, ASME, SAE and ASEE Joint Propulsion Conference and Exhibit No. 32, Lake Buena Vista

Quentmeyer RJ (1977) Experimental Fatigue Life Investigation of Cylindrical Thrust Chambers. In: AIAA/SAE Propulsion Conference No. 13. American Instilute of Aeronautics and Astronautics, 1290 Avenuo of the Americas, New York, N.Y. 10019

Quentmeyer, RJ (1988) Thrust chamber thermal barrier coating techniques. NASA Rep Tech Memorandum NASA TM-100933

Raj SV, Ghosn LJ, Robinson C, Humphrey D (2007) High heat flux exposures of coated GRCop-84 substrates. Mater Sci Eng A 457:300-312
Schloesser J, Bäker M, Rösler J (2011) Laser cycling and thermal cycling exposure of thermal barrier coatings on copper substrates. Surf Coat Technol 206:1605-1608

Schloesser J (2014) Mechanische Integrität von Wärmedämmschichten für den Einsatz in Raketenbrennkammern. PhD thesis, Technische Universität Braunschweig, Der Andere Verlag, Uelvesbüll

Seiler P, Bäker M, Rösler J (2013) Multi-scale failure mechanisms of thermal barrier coating systems. Comput Mater Sci 80:27-34

Taylor TA, Walsh PN (2004) Thermal Expansion of MCrAlY Alloys. Surf Coat Technol 177-178:24-31

Taylor TA, Bettridge DF (1996) Development of Al Alloy and Dispersion-Strengthened MCrAlY Coatings. Surf Coat Technol 86-87:9-14

Touloukian YS, Kirby RK, RE Taylor, PD Desai (1975) Thermophysical Properties of Matter 12 - Thermal Expansion - Metallic Elements and Alloys. IFl/Plenum, New York - Washington

Zinkle SJ, Fabritsiev SA (1994) Copper alloys for high heat flux structure applications. At Plasma Mater Interact Data for Fusion 5:163-191

\section{Submit your manuscript to a SpringerOpen ${ }^{\circ}$ journal and benefit from:}

- Convenient online submission

- Rigorous peer review

- Immediate publication on acceptance

- Open access: articles freely available online

- High visibility within the field

- Retaining the copyright to your article

Submit your next manuscript at $>$ springeropen.com 